\title{
AUGMENTED REALITY WISATA MONUMEN BERSEJARAH LAMPUNG BERBASIS MOBILE
}

\author{
Triowali Rosandy ${ }^{1}$, Hermanto ${ }^{2}$, TM Zaini ${ }^{3}$ \\ ${ }^{123}$ Fakultas Ilmu Komputer, Informatics \& Business Institute Darmajaya \\ Jl. Z.A. Pagar Alam No. 93, Bandar Lampung - Indonesia 35142 \\ Telp. (0721) 787214 Fax. (0721) 700261 \\ e-mail : triowali@darmajaya.ac.id, hermanto@darmajaya.ac.id, tmzaini@darmajaya.ac.id
}

\begin{abstract}
Development of 'Virtual' Tourism This historical monument of Lampung-based Mobile is projected as an innovation of socialization and exploration of historical monuments using attractive, informative and interactive computer graphics technology, because it can bring imitation of objects that are socialized so that tourists or visitors can interact and see the beauty directly historical monument objects which are products of national culture.

In contrast to conventional promotions, the technology that will be applied is interactive and more interesting because the information that can be displayed is not only in the form of text and images that are usually found on a website, but also can display 3D objects, as well as animation in real time, so that tourists by using this mobile-based technology as if it can be directly and react with the historical monument of Lampung that is accessed. It is hoped that the application of computer graphics technology to tourism objects can support the dissemination of Indonesian cultural products to the international realm, which is one of the information technologies that is expected to be able to contribute positively to the preservation of Indonesian cultural products. This computer application development was developed using one of the software development methods, namely 'waterfall'. In this study, a series of activities will be carried out such as surveys, observations in order to obtain information on system requirements, design and proceed with the implementation stage by modeling $3 D$ objects of the historical Lampung monument. Furthermore, integration is carried out on the unity application. At the next stage mobile testing is carried out.
\end{abstract}

Keywords - Tourism, virtual object, mobile, monument building

\begin{abstract}
ABSTRAK
Pengembangan Wisata 'Virtual' Monumen bersejarah Lampung Berbasis Mobile ini diproyeksikan sebagai inovasi sosialisasi serta eksplorasi monumen bersejarah menggunakan teknologi komputer grafis yang menarik, informatif serta interaktif, karena dapat menghadirkan tiruan objek yang disosialisasikan sehingga wisatawan atau user pengunjung seolah dapat berinteraksi dan melihat secara langsung keindahan objek monumen bersejarah yang merupakan produk budaya bangsa.

Berbeda dengan promosi konvensional, teknologi yang akan diterapkan ini bersifat interaktif dan lebih menarik karena informasi yang dapat ditampilkan tidak hanya berupa teks dan gambar saja seperti yang biasanya terdapat pada sebuah website, tetapi juga dapat
\end{abstract}


menampilkan objek 3D, serta animasi secara real time, sehingga wisatawan dengan menggunakan teknologi berbasis mobile ini seolah dapat berada langsung dan berineraksi dengan monumen bersejarah lampung yang di aksesnya. Dengan diterapkan teknologi komputer grafis pada objek wisata ini diharapkan dapat mendukung sosialisasi produk budaya Indonesia ke ranah Internasional, yang merupakan salah satu teknologi informasi yang diharapkan mampu memberi kontribusi positif terhadap pelestarian produk budaya Indonesia. Pengembangan aplikasi komputer ini dikembangkan menggunakan salah satu metode pengembangan perangkat lunak yaitu 'waterfall'. Dalam penelitian ini, akan dilakukan serangkaian kegiatan seperti survey, observasi dalam rangka memperoleh informasi kebutuhan sistem, perancangan dan dilanjutkan dengan tahapan implementasi dengan membuat modelling objek 3D monumen bersejarah Lampung. Selanjutnya dilakukan integrasi pada aplikasi unity. Pada tahap selanjutnya dilakukan pengujian mobile.

Kata Kunci - Wisata, virtual object, mobile, monument building

\section{PENDAHULUAN}

Monumen bersejarah Lampung Berbasis Mobile ini diproyeksikan sebagai inovasi sosialisasi serta eksplorasi monumen bersejarah Untuk memajukan sektor pariwisata suatu daerah, perlu dilakukan pengembangan, penyediaan sarana dan fasilitas, pengelolaan serta promosi. Promosi atau pengenalan objek wisata mempunyai posisi yang penting dalam upaya meningkatkan jumlah pengunjung baik wisatawan lokal maupun mancanegara.

Indonesia memiliki kekayaan budaya yang merupakan aset berharga yang perlu dilestarikan serta oleh masyarakat Indonesia. Masing-masing suku bangsa di kepulauan Indonesia memiliki keunikan kesenian, senjata pusaka, tarian, busana rumah adat serta monumen bersejarah. Umumnya monumen bersejarah yang ada di Indonesia memiliki sebutan atau nama serta arsitektur yang menarik dan bernilai seni tinggi karena sarat dengan history dan ornamen etnik .

Monumen bersejarah di daerah seluruh Indonesia dapat dijumpai saat wisatawan berkunjung ke wilayah tersebut. Monumen bersejarah ini menjadi objek yang menarik dan cukup diminati oleh pengunjung karena mempunyai nilai histori dan kebanggaan daerah. Pengunjung yang tertarik akan peninggalan sejarah berupa bangunan atau monumen dapat menikmati keindahan, keunikan dan informasi dengan dengan mendatangi lokasi daerah dimana terdapat monumen bersejarah.

Saat ini dengan kemajuan teknologi komputer khususnya teknologi komputer 
grafis, memungkinkan pengguna ke dalam lingkungan nyata. Berbeda komputer melakukan wisata 'virtual'. dengan teknologi Virtual Reality (VR) Belum banyak aplikasi di Indonesia memiliki fasilitas ini. Beberapa website yang menyediakan fasilitas tur virtual dengan teknik memasang foto-foto yang dikonfigurasikan sedemikian rupa sehingga dapat dieksplorasi $360^{\circ}$. Namun pendekatan menggunakan foto yang merupakan gambar 2 dimensi kurang merepresentasikan 'wisata' yang sesungguhnya.[1]

Untuk memuat konten 3D pada mobile, telah tersedia software pengembang unity yang masih jarang digunakan pengembang. Augmented Reality cukup representatif dan sesuai untuk simulasi wisata virtual.[9] Pengguna yang mengunjungi aplikasi berbasis mobile dapat mengekplorasi atau menjelajah objek yang dimuat. Dengan membuat objek 3D semirip mungkin dengan aslinya serta ditambah fasilitas dan infomasi pendukung, wisatawan dengan teknologi mobilenya seolah melakukan kegiatan menjelajah tempat wisata atau sebuah bangunan.[5]

\section{METODE PENELITIAN}

Teknologi Augmented Reality (AR) merupakan teknologi yang memungkinkan penambahan citra sintetis yang sepenuhnya mengajak pengguna ke dalam lingkungan sintetis, AR memungkinkan pengguna melihat obyek virtual 3D yang ditambahkan ke dalam lingkungan nyata. AR dan VR merupakan bagian dari rangkaian virtual-reality yang selanjutnya disebut dengan mixed-reality (MR). Lingkungan MR memadukan dunia nyata dan obyek virtual dalam tampilan yang sama secara real-time. Teknologi ini dapat meningkatkan persepsi dan interaksi para pemakai dengan dunia nyata terutama dengan AR[3].

Menurut Nazruddin Android adalah aplikasi sistem operasi untuk telepon seluler yang berbasis Linux. Android menyediakan platform terbuka bagi para pengembang untuk menciptakan aplikasi mereka sendiri untuk digunakan oleh bermacam piranti bergerak[7] .

Unity[4] salah satu game engine yang mudah digunakan, hanya membuat objek dan diberikan fungsi untuk menjalankan objek tersebut. Dalam setiap objek mempunyai variabel, variabel inilah yang harus dimengerti supaya dapat membuat game yang berkualitas. Berikut ini adalah bagian-bagian dalam Unity: .Asset yang adalah tempat penyimpanan dalam Unity yang 
menyimpan suara, gambar, video, dan tekstur. Scenes adalah area yang berisikan konten-konten dalam game, seperti membuat sebuah level, membuat menu, tampilan tunggu, dan sebagainya. Game Objects adalah barang yang ada di dalam assets yang dipindah ke dalam scenes, yang dapat digerakkan, diatur ukurannya dan diatur rotasinya. Components adalah reaksi baru, bagi objek seperti collision, memunculkan partikel, dan sebagainya. Script, yang dapat digunakan dalam Unity ada tiga, yaitu Javascript, C\# dan BOO. Prefabs adalah tempat untuk menyimpan satu jenis game objects, sehingga mudah untuk diperbanyak.

\section{HASIL DAN PEMBAHASAN}

\section{A. Desain}

Rancang bangun aplikasi website tur virtual reality rumah adat ini menggunakan metode waterfall [6] yang merupakan salah satu metode dalam (software engineering) Rekayasa Perangkat Lunak, sehingga langkahlangkah pengerjaan aplikasi ini merujuk pada metode tersebut. Metode ini dipilih karena dipandang lebih cocok digunakan untuk pembuatan perangkat lunak yang tidak berorientasi pada permintaan stakeholder atau tidak ada pemesan dalam hal ini.

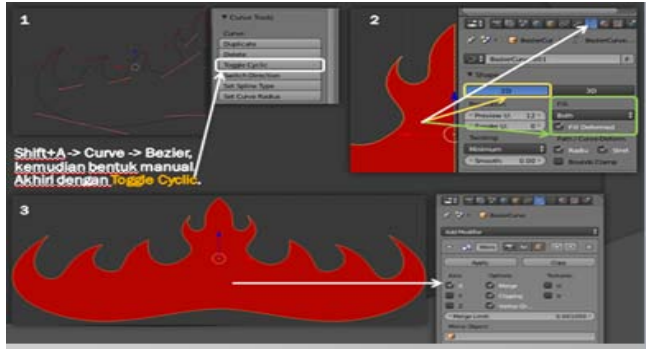

Gambar 1. Proses Rancangan Awal

\section{Pembuatan Bentuk Siger Lampung}

Adapun proses untuk pembuatan bangunan gedung dan lantai luar gedung dibuat dengan geometri box, untuk tiang bulat dibuat dengan geometri cycle, teras di luar gedung dan bangunan warna merah di samping gedung dibuat dengan plane dan untuk keseluruhan geometri yang digunakan harus di extrude, scaling, rotate dan duplikat. Hasil gambar dapat dilihat di bawah ini.

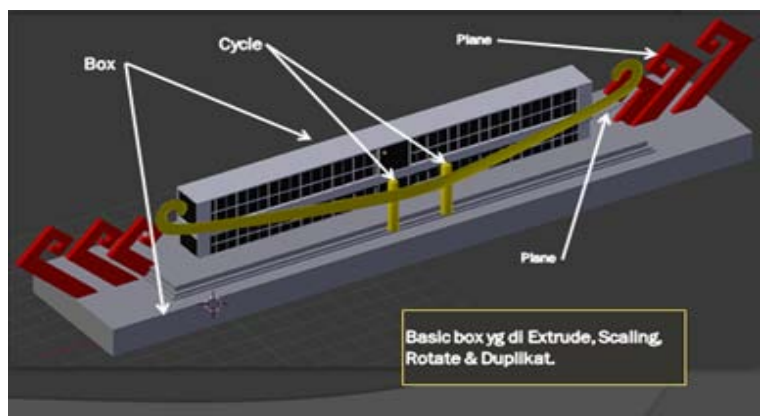

\section{Gambar 2. Proses Rancangan Awal Pembuatan Gedung Monumen}

\section{B. Implementasi}

Implementasi Hasil Desain yang disimpan dalam file berbentuk image yang kemudian di Install pada peralatan mobile android yang berikutnya agar dapat di 
tampilkan sesuai dengan objek 3d yang telah tersimpan untuk mewakili pembacaan file guna di muncilkan dalam aplikasi android (handphone), berikut hasil akhir untuk memunculkan objek monument bersejarah dalanm hal ini monument siger lampung di tunjukkan pada gambar berikut ini.

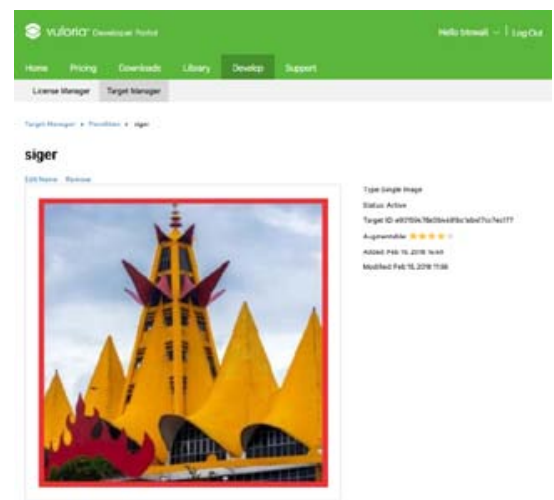

\section{Gambar 3. Image Target}

Hasil Desain yang disimpan dalam file berbentuk image yang kemudian di Install pada peralatan mobile android yang berikutnya agar dapat di tampilkan sesuai dengan objek 3d yang telah tersimpan untuk mewakili pembacaan file guna di muncilkan dalam aplikasi android (handphone), berikut hasil akhir untuk memunculkan objek monument bersejarah dalanm hal ini monument siger lampung di tunjukkan pada gambar berikut ini.

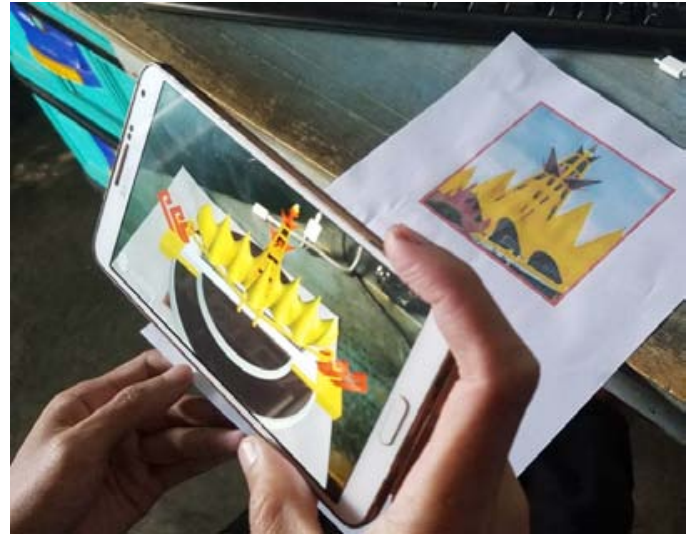

Gambar 4. Hasil Penerapan

Reknologi AR Berbasis Mobile

\section{SIMPULAN}

Implementasi penggunaan Teknologi AR (Augmented Reality) ini dapat di terapkan sebagai salah satu sarana promosi wisata ‘monumen bersejarah' di provinsi lampung dan menjadikan lebih menarik dan interaktif. Dimana objek tiga dimensi (3d) dapat di tampilkan dengan diwakilkan oleh objek 'image' sehingga user yang memiliki Handphone dapat berinteraksi langsung dan dapat melihat tampilan yang lebih interaktif yang mewakili tentang sarana dan aktifitas yang ada pada objek bersejarah.

\section{UCAPAN TERIMAKASIH}

Kami ucapkan terimaksih kepada Direktorat Pendidikan Tinggi Indonesia (DIKTI) sebagai pemberi dana bantuan Hibah Penelitian Dosen Pemula. 


\section{DAFTAR PUSTAKA}

[1] Azuma, R. T. (1997), A Survey of Augmented Reality, Presence, 6(4), hal 355-385

[2] Azuma, R. T. et. al. (2001), Recent Advances in Augmented Reality, IEEE Wagner, D.; Schmalstieg, D. Making Augmented Reality Practical on Mobile Phones, Part 1. IEEE Computer Graphics and Applications, 21(6), hal 34-47

[3] Billinghurst, M., Kim, G. (2007), Interaction Design for Tangible Augmented Reality Applications, Emerging Technologies of Augmented Reality: Interfaces and Design, Idea Group Inc, hal 261- 279.

[4] Billinghurst, M., Kato, H., dan Poupyrev, I. (2001), The MagicBook: Moving. Seamlessly between Reality and Virtuality. IEEE Computer Graphics and Applications, 21(3), hal 6-8.

[5] Billinghurst, M., et al (2000), Virtual Object Manipulation on a Table-top AR Mobile Beacon-Assisted Localization in Wireless Sensor
Networks. Sensors 2009, 9, 27602779. Environment, Proceedings of the IEEE and ACM International Symposium on Augmented Reality (ISAR) hal 111-118..

[6] Pressman, R.S, 2001, "Software Engineering, A Practitioner's Approach”, Fifth Edition, McGrawHill Companies, Inc.

[7] June Safaat, Nazruddin. (2012). Android Pemrograman Aplikasi Mobile Smartphone dan Tablet PC Berbasis Android. Bandung: Informatika.

[8] Sari P. Z., Nugroho, H., Jatmiko, A., Agung, A.2013. Aplikasi Game Action RPG „RUGEN THE WIGOON MASTERPIECE' Pada Platform Android Dengan Menggunakan Unity. Skripsi Program S1 Teknik Informatika Universitas Bina Nusantara. Jakarta Barat.

[9] Ossy, Zaini,TM, Frizka.(2013), Penerapan Optical Character Recognation Pada Penterjemah Inggris <-- > Indonesia Mobile Berbasis Augmented Reality, Jurnal Informatika. 